\title{
Existe uma relação entre nível de renda, desigualdade e pobreza? Um estudo a partir de elasticidades.
}

\author{
Fernando Henrique Taques \\ Mestre em Economia Política pela Pontifica Universidade Católica de São Paulo (PUC - SP). \\ Endereço para contato: Rua Iguatemi, 306 - Itaim Bibi - São Paulo - SP \\ CEP: 01451-010 - E-mail: fernandohtaques@gmail.com
}

\section{Jailson da Conceição Teixeira de Oliveira}

Professor - Universidade Federal da Paraíba e Doutorando do Programa de Pós-Graduação em Economia pelo PPGE/UFPB. Endereço para contato: Rua Castelo Branco - Campus I, UFPB - João Pessoa - PB

CEP: 58051-900 - E-mail: jailson.consultor@gmail.com

Recebido em 21 de maio de 2014. Aceito em 17 de setembro de 2014.

\begin{abstract}
Resumo
A proposta dessa pesquisa é analisar como o crescimento econômico, a desigualdade de renda e a pobreza se relacionam entre si, tendo em vista os apontados levantados pela literatura para a elaboração e condução de políticas sociais que busquem o combate à pobreza e a melhoria na distribuição de renda da população. Serão utilizados dados referentes às unidades federativas do Brasil para o período entre 1995 à 2009, para estimativa das elasticidades renda-pobreza, redistribuição-pobreza, renda-desigualdade e pobreza-desigualdade por meio da metodologia de dados em painel (efeitos fixos, efeitos aletórios e primeiras-diferenças). Os resultados obtidos indicam que políticas públicas voltadas à distribuição mais igualitária da renda são mais efetivas para a redução da pobreza, em comparação às que buscam unicamente o aumento da renda. Por outro lado, políticas que visam reduzir a pobreza são mais efetivas no combate à desigualdade do que as voltadas para o aumento da renda.
\end{abstract}

\section{Palavras-chave}

Crescimento econômico; desigualdade de renda; pobreza; dados em painel

\begin{abstract}
The purpose of this research is to analyze how economic growth, income inequality and poverty relate to each other, in view of the pointed raised in the literature for the preparation and conduct of social policies that seek to combat poverty and improving the distribution income population. Will use data on federal units of Brazil for the period 1995 to 2009 to estimate the elasticities income-poverty, redistribution-poverty, income-inequality and poverty-inequality through methodology of panel data (fixed effects, random effects and first differences). The results indicate that public policies aimed at more equitable income distribution are more effective in reducing poverty, compared to only seeking increased income. On the other hand, policies aimed at reducing poverty are more effective in combating inequality than those toward increasing income.
\end{abstract}

Keywords

Economic growth, income inequality, poverty, panel data.

JEL Classification

I3; D6; C23

Econ. e Desenv., Santa Maria, vol. 26, n.2, p. 21 - 42, jul. - dez. 2014 


\section{INTRODUÇÃO}

De acordo com dados divulgados pelo IBGE (Instituto Brasileiro de Geografia e Estatística), a taxa de pobreza no Brasil, entre 1995 e 2009 caiu cerca de 14\% no país. Neste mesmo período, a desigualdade, mensurada pelo índice de Gini, declinou de 0,60 para 0,54 e o nível de renda per capita média elevou-se acima de $21 \%$.

Estudos de Plotnick e Skidmore (1975), Aaron (1967), Perl e Solnick (1971) e Adams (2002) sugerem que a redução da pobreza está vinculada, em parte, ao aumento no nível de renda. Segundo Thornton et al. (1978), além da renda, as alterações da pobreza podem ser advindas de políticas de transferências de renda, da eficiência do mercado de trabalho ou mesmo da evolução nos níveis de educação.

Os trabalhos de Anderson (1964), Thornton et al. (1978) e Hirsh (1980), através da hipótese do efeito transbordamento (trickle-down), revelam que os benefícios do crescimento ${ }^{1}$ se espalham por todos os segmentos da sociedade, ou seja, o aumento do produto vem acompanhado de redução da pobreza (PINTO e OLIVEIRA, 2010, pgs. 330-331). Isso indica que o crescimento econômico possui efeitos sobre a redução da pobreza e também eleva o nível de emprego ou dos salários reais. Por outro lado, a relação entre desigualdade de renda e nível de renda não apresenta resultados inequívocos. Alesina e Perotti (1996) encontram correlação positiva entre as variáveis, enquanto Rodrik (1994) constatou correlações negativas entre elas.

Por outro lado, há indícios de ausência de correlação entre desigualdade e crescimento econômico, distintamente da conclusão de Kuznets (1955). A hipótese de Kuznets - ou hipótese do U-invertido - foi rejeitada em alguns estudos empíricos, e.g., Ravallion (1995) e Deininger e Squire (1998), que apontam para uma fraca relação entre as variáveis. Barro (2000), por sua vez, não encontra evidências de que as variáveis são correlacionadas.

Há evidências na literatura de que o crescimento contribui na redução da pobreza, desde que a desigualdade seja mantida constante. $\mathrm{O}$ argumento parte da perspectiva que a distribuição da renda joga um papel importante na determinação da pobreza. Para Kimenyi (2006, pg. 11), a pobreza é menos sensível aos aumentos de renda se a desigualdade é maior, pois a capacidade de resposta da pobreza ao crescimento depende dos níveis iniciais de renda e da distribuição desta na população. Alguns trabalhos apontam que se a distribuição se torna menos igualitária, então tende a ocorrer um aumento na pobreza.

Kakwani e Pernia (2000) desenvolveram uma metodologia para mensurar o crescimento pró-pobre. Deste modo, a redução da pobreza é dada pela variação no nível de renda e também por modificações distributivas na renda. Os autores indicam que o crescimento da renda reduz a pobreza, mas se este ganho de renda for acompanhado também de aumento na desigualdade, então a redução da pobreza será menor do que os efeitos obtidos se essa desigualdade fosse constante ou menor.

Sen (2001) discute a relação entre desigualdade e pobreza a partir de indicadores. Analisando medidas de pobreza, a saber, a taxa de indidência - H (head-count ratio) e hiato de renda - I (income gap), o autor observa que, de maneira precipitada, pode-se concluir que a junção de ambas as medidas seria adequada para mensurar a pobreza, uma vez que estas são

\footnotetext{
${ }^{1}$ Nessa pesquisa o termo crescimento econômico representa o aumento no nível de renda.
}

RE\&D Econ.e Desenv., Santa Maria, vol. 26, n.2, p. 21 - 42, jul. - dez. 2014 
medidas complementares. $\mathrm{O}$ argumento do autor é baseado na metodologia dos indicadores que não consideram a distribuição de renda entre os indivíduos mais pobres da população ${ }^{2}$.

Bourguignon (2004) discute que as estratégias de desenvolvimento residem nas interações entre distribuição de renda e crescimento e não entre pobreza e crescimento unicamente. Nessa abordagem, as estratégias devem ser direcionadas para a eliminação da pobreza absoluta via políticas combinatórias que promovam tanto o crescimento quanto uma melhora distributiva. Neste mesmo caminho, Son (2007) assume que o padrão de crescimento é determinado pelas mudanças tanto da pobreza quanto da desigualdade.

É comum na literatura a escolha de um indicador de extensão da pobreza para analisar a relação entre crescimento econômico e pobreza como, por exemplo, a proporção de pobres. A opção deste índice revela que houve uma redução na proporção de pobres, mas não se pode dizer a que distância os mais pobres se situam da linha de pobreza determinada para o estudo. Assim, assume-se que esta parcela da população possua o mesmo nível de privações, independentemente do quão distante esteja da linha de pobreza. Nesse caso, um aumento na renda pode situar indivíduos ligeiramente acima da linha de pobreza, não indicando de maneira precisa o efeito dos ganhos de renda para os mais pobres. Bourguignon (2002), nesse sentido, avança ao sugerir a incorporação de um componente de desigualdade de renda com o intuito de captar se o crescimento foi, de fato, a favor dos mais pobres.

A partir deste referencial, o objetivo deste trabalho é identificar relações entre nível de renda, pobreza e desigualdade através da estimativa de elasticidades. Para tanto, parte de dados dos estados brasileiros no período entre 1995 e 2009. A metodologia empregada consiste no método de dados em painel (primeiras-diferenças e efeitos fixo e aleatório). A justificativa para a investigação mencionada reside no fato de que, conforme sugere a literatura, as variáveis de estudos contribuem na elaboração e condução de políticas mais igualitárias.

Não caberia aqui apresentar uma revisão extensa da literatura que envolve a relação entre crescimento e distribuição de renda, e também crescimento e pobreza dada sua elevada extensão e complexidade, mas sim apresentar algumas das principais fundamentações e contribuições acerca deste debate.

Este artigo está estruturado em quatro partes, além desta introdução e da conclusão. $\mathrm{Na}$ primeira há uma breve revisão teórica da literatura que examina a relação entre desigualdade de renda, pobreza e crescimento econômico. Na segunda são listadas evidências empíricas da estimativa de elasticidades entre as variáveis de interesse, tanto para o Brasil quanto para outros países. A terceira seção apresenta a descrição dos dados e a metodologia empregada para as estimativas das elasticidades. Por fim, na quarta parte são apresentados os resultados das estimativas e o suporte destes na formulação de políticas públicas.

\section{CONSIDERAÇÕES TEÓRICAS SOBRE A RELAÇÃO TRIANGULAR ENTRE NÍVEL DE RENDA, POBREZA E DESIGUALDADE}

Determinar como o nível de renda, a pobreza e a desigualdade são afetados entre si não é algo trivial. Neste sentido, primeiramente, cabe definir cada um destes conceitos.

\footnotetext{
${ }^{2}$ Ver Comim e Bagolin (2002) para uma revisão da abordagem multidimensional da pobreza.
} 
Bourguignon (2004) apresenta as seguintes definições: a pobreza é medida pela proporção da população abaixo da linha da pobreza; a desigualdade (ou distribuição) representa as disparidades de rendimentos relativos da população e, por fim, o crescimento indica a variação percentual no nível de bem-estar médio, medido através do consumo ou da renda. Partindo destes conceitos serão expostas as argumentações envolvendo a relação entre as três dimensões de interesse.

O trade-off entre desigualdade de renda e crescimento passou a ser amplamente debatido na literatura econômica a partir do trabalho seminal de Kuznets (1955). Neste estudo, Kuznets aborda as relações entre nível de renda e desigualdade a partir de uma economia dual (um setor agrícola e outro não agrícola). A hipótese de Kuznets (ou hipótese do U-invertido) é baseada no fato de que em estágios iniciais de crescimento a desigualdade de renda se elevaria, mas com o aumento da renda, ao longo do tempo, a distribuição se tornaria mais igualitária. $^{3}$

Recentemente, diversos estudos demonstraram, de maneira ambígua, a contribuição da desigualdade de renda sobre o crescimento econômico. Barreto (2005) levanta argumentos que sustentam uma relação negativa desta hipótese: (a) tanto gastos públicos quanto uma carga tributária inversamente relacionada à renda agiriam negativamente sobre a acumulação de capital e, por conseguinte, sobre o crescimento econômico; (b) a instabilidade advinda de sociedades desiguais desencorajaria a acumulação de capital pelas incertezas originárias tanto da esfera política quanto social; (c) considerando que capital humano e crescimento apresentam uma relação positiva, então a restrição ao crédito reduziria o investimento em capital humano da parcela mais pobre da população; (d) se existem retornos decrescentes de investimento em capital individual e se estes são uma função crescente das dotações iniciais, então em uma população com distribuição menos igualitária os retornos marginais beneficiariam os mais ricos em detrimento dos mais pobres, desde que a variação na renda seja positiva (ALESINA e RODRIK (1994); ALESINA e PEROTI (1996); GALOR e ZEIRA (1993); AGHION et al. (1999)).

Portanto, conforme Barreto (2005), o efeito que o crescimento econômico pode exercer sobre a distribuição de renda pode ocorrer através dos seguintes canais: distribuição dos recursos entre setores, modificação nos preços relativos, recursos de fatores (trabalho, capital físico, capital humano, dentre outros) e suas respectivas dotações para os agentes, independentemente da estrutura de mercado. Em contrapartida, este mesmo crescimento tende a gerar mudanças instituicionais em virtude tanto da maior procura por bens e serviços quanto pela participação mais ativa da sociedade (BOURGUIGNON, (2004); JUSTMAN e GRADSTEIN, (1999)). Por outro lado, segundo Barro (2000), o efeito da desigualdade sobre a taxa de crescimento econômico é originário das imperfeições do mercado de crédito, do regime político do país, das distorções nas taxas de poupança e também de conflitos sociais.

$\mathrm{O}$ argumento do mercado de crédito é centrado na maior dificuldade de acesso dos mais pobres a esse mercado. Isso decorre de informações assimétricas e limitações institucionais, pois se os mais ricos obtêm recursos a uma taxa de juros inferior em

\footnotetext{
3 A análise de Kuznets (1955) parte da concepção de que os setores (agrícola e industrializado) possuem diferenciais de produtividade, o que afetaria a distribuição a partir do maior nível de renda. Ver Fields (2001) para um survey da hipótese de Kuznets.
}

RE\&D Econ.e Desenv., Santa Maria, vol. 26, n.2, p. 21 - 42, jul. - dez. 2014 
comparação aos mais pobres, então uma parcela considerável da população de menor renda deixará de investir ${ }^{4}$. Porém, se os recursos fossem distribuídos de forma mais igualitária entre a população, então os mais pobres teriam menor necessidade de contrair empréstimos e maior incentivo para empreender. Logo, a redistribuição da renda direcionada dos mais ricos aos mais pobres tende a implicar em um aumento no nível de investimento e/ou propiciar uma taxa de retorno do capital maior (GALOR e ZEIRA, (1993); BANERJEE e NEWMAN (1993); AGHION e BOLTON (1997); BOURGUIGNON (2004)).

Sob uma perspectiva política, Stevans e Sessions (2002) assumem que há uma forte tendência em longo prazo de correlação negativa entre pobreza e crescimento econômico. Segundo os autores, essa condição geraria menos incentivos para alocar recursos em programas voltados à redução da pobreza. A respeito do regime político alguns autores sugerem que, em um ambiente democrático, o eleitor mediano, que tende a ser pobre, influencia diretamente a escolha do candidato. Esse cenário beneficiaria candidatos com políticas igualitárias de renda, o que pode determinar o patamar de crescimento da economia (PERSSON e TABELLINI (1994), ALESINA e RODRIK (1994)).

Argumenta-se ainda que modificações no padrão distributivo da população, advindos ou não de decisões do eleitor mediano, podem incorrer em distorções na taxa de poupança e, por conseguinte, no nível de produto. Temos que, por exemplo, uma redução na taxa de poupança tende a reduzir a taxa de crescimento da economia (BARROS e GOMES, 2007).

Por fim, a análise dos conflitos sociais e instabilidade, apresentada por Alesina e Perotti (1996), possui sua fundamentação na desigualdade de renda. Neste caso, se a desigualdade pode gerar maior instabilidade política, então também pode influenciar diretamente o nível de investimento.

Segundo Barreto (2005), há argumentos que defendem a idéia de que a desigualdade contribui no processo de crescimento econômico e que são pautados nas seguintes premissas: (a) se a propensão a poupar da população mais rica é maior em comparação aos mais pobres, então a taxa de investimento em uma economia mais desigual propiciaria um maior nível de renda, e (b) em economias onde não há mercado de capitais desenvolvido que permita a captação de recursos para pequenos investidores, a concentração de renda facilita a disponibilidade de tais recrusos para investimentos (BOURGUIGNON (1981); MIRRLEES (1971)).

De fato, alguns autores revelam que o efeito do crescimento econômico sobre a desigualdade de renda é nulo (DEININGER e SQUIRE (1996); CHEN e RAVALLION (1997); EASTERLY (1999); DOLLAR e KRAAY (2002)). Contudo, para Bourguignon (2004), a discussão, na realidade, reside no fato de que tanto o crescimento quanto a distribuição são independentes ou fortemente relacionados entre si.

Sobre pobreza e taxa de crescimento econômico, Todaro e Smith (2003, pgs. 226 e 227) elencam cinco razões pelas quais políticas direcionadas para a redução da pobreza não levam, necessariamente, a uma menor taxa de crescimento:

(a) A pobreza generalizada cria condições para que os mais pobres não tenham acesso ao crédito, o que os torna incapazes de financiar a educação de seus filhos.

\footnotetext{
${ }^{4}$ A dificuldade de acesso dos mais pobres ao mercado de crédito advém da imperfeição dos mercados de crédito, da ausência de garantias inerentes aos empréstimos e pela própria pobreza que os impede de investir (PIKETTY e SAEZ, 1993).
} 
Considerando a ausência de oportunidades de investimento (físico ou monetário), ter muitos filhos passa a ser uma fonte de segurança financeira para a velhice. A combinação destes fatores faz com que o crescimento per capita seja menor do seria se houvesse uma igualdade maior;

(b) O senso comum, apoiado por dados empíricos, demonstra que, ao contrário da experiência histórica dos países hoje desenvolvidos, os ricos contemporâneos de países pobres, em geral, não são conhecidos pelo ato de poupar ou investir proporção substancial de sua renda na economia local;

(c) A baixa renda e qualidade de vida dos pobres que se manifesta em problemas de saúde, nutrição e educação que podem reduzir o nível de produtividade da economia e, assim, conduzir de maneira direta ou indireta a economia a uma trajetória de crescimento mais lento. Então, estratégias para aumentar a renda e a qualidade de vida dos pobres podem contribuir tanto no nível de produtividade quanto para a economia como um todo;

(d) O aumento no nível de renda dos mais pobres estimula um aumento na demanda global por produtos locais (como vestuário e alimentos), enquanto que os mais ricos tendem a gastar sua renda adicional em artigos de luxo importados. A crescente demanda por produtos locais fornece um maior estímulo à produção, ao emprego e ao investimento local. Tal perspectiva criaria condições para o rápido crescimento econômico e uma maior participação no crescimento;

(e) Uma redução da pobreza em massa pode estimular a expansão econômica através de incentivos à participação do público no processo de desenvolvimento. Pelo contrário, as disparidades de renda e a substancial pobreza absoluta podem atuar como desincentivos para o progresso da economia.

Os autores discordam que há um trade-off entre crescimento e pobreza, pois defendem que a promoção do crescimento econômico rápido e a redução da pobreza não são objetivos mutuamente contraditórios 5 .

A literatura sobre esta relação tem sido fundamentada na teoria de crescimento própobre. Na realidade, esta teoria sugere diversas abordagens distintas:

Uma abordagem mais simplista considera como pró-pobre o crescimento capaz de reduzir a pobreza, independente do nível de desigualdade. Assim, somente se a renda dos considerados pobres estagnar ou se reduzir um episódio de crescimento não será considerado pró-pobre (RAVALLION e CHEN, $2003^{6}$ apud ARAUJO et al., 2009, pg. 84).

Já Ravallion (2004) apresenta outra definição de crescimento pró-pobre:

Outra definição seria que o crescimento é pró-pobre se a renda dos pobres crescer proporcionalmente mais do que a dos não-pobres, o que implica concomitante redução da desigualdade de renda relativa. Uma recessão seria pró-pobre se os pobres perderem menos proporcionalmente aos não-pobres, isto é, se a redução da

\footnotetext{
${ }^{5}$ Certainly, the close relationship between economic growth and progress among the poor does not by itself indicate causality. Some of the effect may run from improved incomes, education, and health among the poor to faster overall growth (TODARO e SMITH, 2003, pg. 229).

${ }^{6}$ RAVALLION, M.; CHEN, S. Measuring pro-poor growth. Economic Letters, n. 78, p. 93-99, 2003.
}

RE\&D Econ. e Desenv., Santa Maria, vol. 26, n.2, p. 21 - 42, jul. - dez. 2014 
renda for acompanhada por uma melhora distributiva em favor dos menos favorecidos (RAVALLION, $2004^{7}$ apud ARAUJO et al., 2009, pg. 85).

Envolvendo nesta discussão o conceito de igualdade na distribuição, Matias et al. (2010, pg. 3) argumentam que variações ocorridas na proporção de pobres irão depender das variações do nível de renda e de variações em sua distribuição, ou ainda, do crescimento da renda e de variações no nível de desigualdade.

A literatura demonstra diversos argumentos de que o crescimento econômico é um dos componentes para a redução da pobreza (FIELDS (2001); RAY (1998)). Porém, conforme sugerem ARAUJO et al. (2009), o efeito do crescimento econômico é dependente da desigualdade de renda e, por consequência, da própria pobreza.

De Janvry e Sadoulet (2000), por sua vez, elencam ainda uma série de variáveis que influenciam a trajetória tanto da pobreza quanto da desigualdade de renda, segmentadas em quatro categorias. Primeiramente, considera-se o papel do crescimento da renda per capita agregada, onde a redução da pobreza é dada parcialmente pelo crescimento da renda agregada, todavia as conclusões da relação entre esta última e a desigualdade de renda são divergentes (ver PSACHAROPOULOS et al. (1995); RAVALLION e CHEN (1997)). As mudanças na renda agregada não podem ser atribuídas de maneira igualmente eficazes para determinar tanto o nível de pobreza quanto de desigualdade, pois:

First, there may exist an asymmetry in the relationship between changes in poverty and inequality and changes in income associated with growth and with recession. For instance, a 1 percent increase in Gross National Income per capita (GNIpc) may have less effect on poverty or inequality than a 1 percent fall in GNIpc. Whether this difference exists or not has, however, not been pursued in past empirical analyses. As examples, the Psacharopoulos et al. (1995) and the Ravallion and Chen (1997) studies work with scatters of points that relate changes in poverty and inequality to changes in income. The negative relation between poverty/inequality and per capita income can come from growth as well as from recession, and no attempt is made to see if the strength of this relation differs as income rises or falls. Second, the effect of income growth on poverty and inequality may also differ by policy context. While most previous analyses of the Latin American experience have focused on the 1980s, the effect of GNIpc growth on poverty and inequality can be contrasted between the ISI context that prevailed before the structural adjustment reforms and the open economy context that was introduced by the reforms. The 1990 World Development Report (World Bank, 1990) stressed the importance of the labor intensity of growth in reducing poverty. With transition from IS1 to more open economy industrialization, the labor intensity of growths should have increased, and hence also the income elasticity of poverty (DE JANVRY e SADOULET, 2000, pg. 270).

O segundo fator é dado pelo papel da qualidade do crescimento na renda agregada vinculado a outras duas hipóteses: (a) a instabilidade do crescimento (medida pelo coeficiente de variação da renda per capita em torno de sua linha de tendência) que está associada à mensuração das oscilações do nível de renda em cada período de tempo. Assim, identificar flutuações entre períodos (seja de crescimento ou recessão) podem auxiliar na determinação da trajetória da pobreza; e (b) a composição setorial do crescimento contemplando os setores primário, secundário e terciário pode implicar em divergência no efeito do crescimento sobre a pobreza, principalmente entre setores agrícola e não-agrícola.

\footnotetext{
${ }^{7}$ RAVALLION, M. Pro-poor growth: a primer. World Bank - Policy Research Working Papers, n. 3242, 2004.
} 
O terceiro aspecto remete ao desempenho macroeconômico. A inflação (ou hiperinflação) e a depreciação da taxa de câmbio real têm revelado associação positiva com o aumento da pobreza. $\mathrm{O}$ aumento no nível geral de preços gera arrocho nos salários reais, ao passo que a desvalorização da taxa de câmbio real pode trazer consigo queda nos salários reais dos setores formais, elevando a pobreza nas áreas urbanas.

Por fim, o quarto fator é dado pelo papel estrutural e das condições iniciais da economia. Para tanto, considera-se o efeito de variáveis estruturais (proporção da renda agrícola na constituição do produto interno bruto e a respectiva parcela da população nas áreas rurais, além da taxa de crescimento populacional) que afetam a pobreza no meio rural, vis-à-vis o meio urbano, ou mesmo o padrão distributivo da sociedade.

A educação, por outro lado, possui dois canais pelos quais pode auxiliar tanto na redução das disparidades de renda quanto na queda pobreza: o primeiro deles é pelo aumento de matrículas no ensino secundário que tende a tornar as disparidades de rendas menores na população e, por conseguinte, reduzir a pobreza; ao passo que o segundo aspecto leva em conta o aumento da produtividade dos pobres, o que pode refletir em salários mais elevados.

Para complementar a análise, De Janvry e Sadoulet (2000) incorporam à análise os níveis iniciais de renda per capita, desigualdade e pobreza. A partir do debate apresentado na literatura, consideram que níveis mais baixos de renda per capita podem estar associados a taxas de crescimento mais elevadas, o que conduziria a uma redução na pobreza. Sobre a desigualdade depreende-se que se houver um efeito de inércia, a desigualdade de renda no período inicial pode influenciar a trajetória de longo prazo. De maneira análoga, os níveis iniciais de pobreza mais elevados tendem a sugerir uma menor elasticidade-renda da pobreza ou mesmo produzir menores efeitos de equalização sobre o crescimento da renda.

Deste modo, os aspectos teóricos levantados suscitaram diversos estudos empíricos para verificar a relação existente entre nível de renda, pobreza e desigualdade de renda, inclusive com dados referentes ao Brasil. Na seção seguinte alguns destes trabalhos serão descritos sob distintas metodologias e níveis de análise.

\section{REVISÃO EMPÍRICA}

A partir deste referencial teórico, uma série de autores realizaram estimativas da elasticidade renda-pobreza - ou elasticidade crescimento da probreza (ECP). Por outro lado, estimativas da elasticidade renda-desigualdade são mais escassas. ${ }^{8}$ Segundo Kimenyi (2006), se a elasticidade crescimento da pobreza é maior do que 1 (um), então isso significa que uma pequena mudança na renda resultará numa diminuição proporcionalmente maior na pobreza. Então, coeteris paribus, quanto maior a ECP, maior será a redução na pobreza para uma determinada taxa de crescimento, ou seja, mais pró-pobre será o crescimento.

\footnotetext{
${ }^{8}$ Além da estimativa de elasticidades, a literatura sugere ainda outras metodologias para mensurar o crescimento pró-pobre, tais como: taxa de crescimento pró-pobre (RAVALLION e CHEN, 2003); índice de crescimento própobre (KAKWANI e PERNIA, 2000), taxa de crescimento pobreza-equivalente (KAKWANI e SON, 2002) e curva crescimento pobreza (SON, 2003).
}

RE\&D Econ. e Desenv., Santa Maria, vol. 26, n.2, p. 21 - 42, jul. - dez. 2014 
Tabela 1 - Evidências da elasticidade renda-pobreza

\begin{tabular}{|c|c|c|c|c|}
\hline Autor & Método & Período & $\begin{array}{c}\text { Nível de } \\
\text { Análise }\end{array}$ & Resultados \\
\hline $\begin{array}{c}\text { Stevans e } \\
\text { Sessions (2002) }\end{array}$ & $\begin{array}{l}\text { Elasticidade renda-pobreza estimada a } \\
\text { partir de um modelo de correção de } \\
\text { erros }\end{array}$ & $\begin{array}{c}\text { Décadas } \\
\text { de } 1960 \text { à } \\
1990\end{array}$ & $\begin{array}{l}\text { Estados } \\
\text { Unidos }\end{array}$ & $\begin{array}{l}\text { Aumentos no crescimento econômico estão } \\
\text { relacionados a reduções na taxa de pobreza }\end{array}$ \\
\hline $\begin{array}{l}\text { Meng et al. } \\
\quad(2005)\end{array}$ & $\begin{array}{l}\text { Elasticidade renda-pobreza a partir do } \\
\text { método de cross-section }\end{array}$ & $\begin{array}{c}1986- \\
2000\end{array}$ & China & $\begin{array}{l}\text { Aumento na pobreza está associado ao } \\
\text { crescimento nos preços dos alimentos e aos } \\
\text { custos subsidiados pelo Estado }\end{array}$ \\
\hline Adams (2004) & $\begin{array}{l}\text { Elasticidade } \\
\text { através do método de mimento-pobreza } \\
\text { quadrados ordinários (MQO) para } \\
\text { dados em painel }\end{array}$ & $\begin{array}{c}\text { Décadas } \\
\text { de } 1980 \text { e } \\
1990\end{array}$ & $\begin{array}{c}60 \text { países em } \\
\text { desenvolvim } \\
\text { ento }\end{array}$ & $\begin{array}{l}\text { Crescimento econômico reduz a pobreza, mas } \\
\text { a redução está associada à desigualdade de } \\
\text { renda }\end{array}$ \\
\hline Wodon (1999) & $\begin{array}{l}\text { Elasticidade crescimento-pobreza a } \\
\text { partir de dados em painel }\end{array}$ & $\begin{array}{c}1983 \text { à } \\
1996\end{array}$ & Bangladesh & $\begin{array}{l}\text { O crescimento reduz a pobreza tanto nas } \\
\text { zonas urbanas quanto rurais e esta redução } \\
\text { está associada à desigualdade nas áreas } \\
\text { urbanas }\end{array}$ \\
\hline $\begin{array}{l}\text { Hoffmann } \\
(2005)\end{array}$ & $\begin{array}{l}\text { Elasticidade da proporção de pobres em } \\
\text { relação ao rendimento médio e o índice } \\
\text { de Gini a partir de parâmetros da } \\
\text { distribuição log-normal do rendimento }\end{array}$ & $\begin{array}{c}1999 \\
2001 \mathrm{e} \\
2002\end{array}$ & $\begin{array}{l}\text { Estados } \\
\text { brasileiros }\end{array}$ & $\begin{array}{l}\text { Valor absoluto da elasticidade cresceria com o } \\
\text { aumento do rendimento médio e decresceria } \\
\text { com maior nível de desigualdade }\end{array}$ \\
\hline $\begin{array}{l}\text { Tochetto et al. } \\
\text { (2004) }\end{array}$ & $\begin{array}{l}\text { Elasticidade da pobreza em relação ao } \\
\text { crescimento do PIB do setor não } \\
\text { agrícola }\end{array}$ & $\begin{array}{c}1981 \text { à } \\
2002\end{array}$ & $\begin{array}{c}\text { Estados } \\
\text { brasileiros } \\
\text { selecionados }\end{array}$ & $\begin{array}{l}\text { Heterogeneidade de elasticidades entre os } \\
\text { estados }\end{array}$ \\
\hline $\begin{array}{c}\text { De Lima, } \\
\text { Barreto e } \\
\text { Marinho (2003) }\end{array}$ & $\begin{array}{l}\text { Dados em painel para estimar as } \\
\text { elasticidades renda-pobreza } \\
\text { desigualdade-pobreza }\end{array}$ & $\begin{array}{c}1985 \text { à } \\
1999\end{array}$ & $\begin{array}{l}\text { Estados } \\
\text { brasileiros }\end{array}$ & Pobreza é sensível às políticas igualitárias \\
\hline Neder (2004) & $\begin{array}{l}\text { Elasticidade de medidas de pobreza em } \\
\text { relação à renda média e à desigualdade } \\
\text { (indicada pelo Índice de Gini) }\end{array}$ & $\begin{array}{c}1995 \mathrm{e} \\
2001\end{array}$ & $\begin{array}{l}\text { Áreas rurais } \\
\text { (regiões e } \\
\text { estados) do } \\
\text { Brasil } \\
\end{array}$ & $\begin{array}{l}\text { A elasticidade da pobreza cresce com o } \\
\text { desenvolvimento das regiões e a distribuição } \\
\text { desigual é um entrave ao alívio da pobreza }\end{array}$ \\
\hline Coelho (2009) & $\begin{array}{l}\text { Dados em painel para estimar a } \\
\text { elasticidade renda e desigualdade da } \\
\text { extrema indigência }\end{array}$ & $\begin{array}{c}1995 \text { à } \\
2007\end{array}$ & $\begin{array}{l}\text { Estados } \\
\text { brasileiros }\end{array}$ & $\begin{array}{l}\text { A redução da desigualdade possui um efeito } \\
\text { mais expressivo para os mais pobres do que o } \\
\text { aumento da renda média }\end{array}$ \\
\hline $\begin{array}{l}\text { Salvato et al. } \\
\quad \text { (2007) }\end{array}$ & $\begin{array}{l}\text { Elasticidades da redução da pobreza e } \\
\text { da indigência em relação ao } \\
\text { crescimento econômico e à taxa de } \\
\text { variação da desigualdade de renda }\end{array}$ & $\begin{array}{l}1991 \mathrm{e} \\
2000\end{array}$ & $\begin{array}{l}\text { Municípios } \\
\text { em distintos } \\
\text { níveis de } \\
\text { agregação } \\
\end{array}$ & $\begin{array}{l}\text { Maior elasticidade crescimento da redução da } \\
\text { pobreza na região sudeste. Nota-se uma } \\
\text { correlação negativa entre o módulo da } \\
\text { elasticidade e a desigualdade inicial }\end{array}$ \\
\hline Resende (2008) & $\begin{array}{l}\text { Elasticidade pobreza-crescimento } \\
\text { através de um modelo de MQO a partir } \\
\text { de duas medidas de pobreza (proporção } \\
\text { de indigentes e proporção de pobres) }\end{array}$ & $\begin{array}{l}1991 \mathrm{e} \\
2000\end{array}$ & $\begin{array}{l}\text { Municípios } \\
\text { mineiros }\end{array}$ & $\begin{array}{l}\text { Maior elasticidade pobreza-crescimento em } \\
\text { algumas regiões em detrimento de outras } \\
\text { (relação válida para os dois indicadores de } \\
\text { pobreza) }\end{array}$ \\
\hline $\begin{array}{l}\text { Matias et al. } \\
\quad(2010)\end{array}$ & $\begin{array}{l}\text { Elasticidade crescimento da pobreza e } \\
\text { desigualdade da pobreza }\end{array}$ & $\begin{array}{l}1995 \text { à } \\
2007\end{array}$ & $\begin{array}{l}\text { Unidades } \\
\text { federativas } \\
\text { do Brasil }\end{array}$ & $\begin{array}{l}\text { Grande disparidade inter-estadual nas } \\
\text { elasticidades crescimento da pobreza em que } \\
\text { unidades menos ricos apresentam menor } \\
\text { elasticidade crescimento da pobreza }\end{array}$ \\
\hline $\begin{array}{l}\text { Pinto e Oliveira } \\
\quad(2010)\end{array}$ & $\begin{array}{l}\text { Elasticidade da pobreza em relação à } \\
\text { renda e à desigualdade }\end{array}$ & $\begin{array}{c}1995 \mathrm{à} \\
2007\end{array}$ & $\begin{array}{l}\text { Brasil e suas } \\
\text { unidades } \\
\text { federativas }\end{array}$ & $\begin{array}{l}\text { A pobreza caiu rapidamente desde } 2001 \text {, mas } \\
\text { ainda existe uma grande discrepância entre } \\
\text { estados e regiões }\end{array}$ \\
\hline $\begin{array}{l}\text { De França } \\
(2010)\end{array}$ & $\begin{array}{l}\text { Elasticidade renda-pobreza } \\
\text { desigualdade-pobreza estimadas } \\
\text { método de dados em painel }\end{array}$ & $\begin{array}{l}1995 \text { à } \\
2005\end{array}$ & $\begin{array}{l}\text { Unidades } \\
\text { federativas } \\
\text { do Brasil }\end{array}$ & $\begin{array}{l}\text { A redução da desigualdade tem maior efeito } \\
\text { na redução dos níveis de pobreza que o } \\
\text { aumento da renda média }\end{array}$ \\
\hline $\begin{array}{l}\text { Silveira Neto } \\
\text { (2005) }\end{array}$ & $\begin{array}{l}\text { Elasticidade pobreza-crescimento a } \\
\text { partir do método de cross-section }\end{array}$ & $\begin{array}{l}1991 \mathrm{e} \\
2000\end{array}$ & $\begin{array}{l}\text { Região } \\
\text { nordeste do } \\
\text { Brasil }\end{array}$ & $\begin{array}{l}\text { A baixa qualidade do crescimento nordestino } \\
\text { está associada ao elevado nível de } \\
\text { desigualdade na posse de ativos produtivos }\end{array}$ \\
\hline $\begin{array}{c}\text { Marinho e } \\
\text { Soares (2003) }\end{array}$ & $\begin{array}{l}\text { Elasticidade da renda média sobre a } \\
\text { pobreza a partir com dados em painel }\end{array}$ & $\begin{array}{c}1985 \text { à } \\
1999\end{array}$ & $\begin{array}{l}26 \text { estados } \\
\text { brasileiros }\end{array}$ & $\begin{array}{l}\text { Quanto maior a renda média, maior o valor } \\
\text { absoluto da elasticidade e quanto maior a } \\
\text { concentração, menor o valor absoluto da } \\
\text { elasticidade }\end{array}$ \\
\hline
\end{tabular}

Fonte: Elaboração dos autores 
Um dos trabalhos pioneiros para a estimativa da elasticidade renda-pobreza partiu de Datt e Ravallion (1992). Os autores desenvolvem um método através de um modelo de regressão linear do tipo log-log para dados da Índia e Brasil. Consideram-se as seguintes variáveis de interesse na análise: proporção de pobres, renda per capita e a variação de um indicador de desigualdade. Os resultados obtidos revelam que o nível de pobreza mais elevado na Índia reduziu o consumo médio da população, ao passo que a pior distribuição de renda no Brasil possibilitou uma redução na diferença da pobreza entre os países.

Ravallion (1997, 2004) estima as elasticidades renda-pobreza e renda-desigualdade. As estimativas indicam que o acréscimo de $1 \%$ na renda geraria uma queda de $4,3 \%$ na pobreza para países de baixa desigualdade, ou então, de $0,6 \%$ para países com elevada desigualdade. Logo, conclui o autor que o aumento no nível de renda acompanhado por uma queda na desigualdade terá maior efeito sobre a pobreza.

Fosu (2010) utiliza o método de dados em painel desbalanceado para estimar as elasticidades renda-pobreza e pobreza-desigualdade para uma série de países ao longo de vinte e cinco anos. Como resultado, conclui que a elasticidade pobreza-desigualdade tende a ser maior que a elasticidade renda-pobreza. Logo, a redução na desigualdade sugere um impacto mais eficaz na redução da pobreza.

Bourguignon (2002) parte de uma distribuição log-normal e estima a elasticidade renda-pobreza para diversos países e associa níveis mais elevados de renda a uma maior elasticidade.

A estimativa da elasticidade crescimento da pobreza de Kakwani, Khandker e Son (2004) leva em consideração os níveis iniciais de desenvolvimento. Sob esta perspectiva e assumindo a complexidade da relação entre crescimento e pobreza, concluem os autores que níveis iniciais mais elevados de desenvolvimento conduzem a uma redução maior no nível de pobreza.

Para Bourguignon (2002), Bourguignon, Ferreira e Walton (2007), Ravallion (1997) e Kimenyi (2006), a interpretação das elasticidades deve ser vista com cautela, pois esta é uma medida sensível ao indicador de pobreza. Além disto, os resultados da elasticidade podem ser enganosos, pois se for considerado, e.g., que a taxa de crescimento econômico é zero e há uma pequena alteração no nível de pobreza (neste caso, uma redução), então o cenário conduziria a uma elasticidade crescimento-pobreza infinita (KIMENYI, 2006, pg. 11).

Haque (2009), por outro lado, parte do pressuposto teórico de Kuznets (1955) para estimar a elasticidade renda-desigualdade. $O$ autor busca compreender os efeitos do desenvolvimento econômico sobre a distribuição de renda para a Austrália no período 19702000, a partir de dados de desenvolvimento e desigualdade de renda. Como conclusão, obtém resultados que sustentam que os pobres se tornaram relativamente mais pobres em um período de desenvolvimento da economia australiana. Sob a hipótese de Kuznets, as evidências indicam que a desigualdade de renda pode elevar-se em qualquer estágio do desenvolvimento e não apenas inicialmente.

De fato, tal como exposto nas duas seções anteriores, a relação triangular entre nível de renda, pobreza e desigualdade não apresenta resultados inequívocos. Partindo deste contexto, na seção seguinte serão apresentadas a base de dados e as respectivas metodologias para as estimativas das elasticidades empregadas neste trabalho.

RE\&D Econ.e Desenv., Santa Maria, vol. 26, n.2, p. 21 -42, jul. - dez. 2014 


\section{DESCRIÇÃO DOS DADOS E METODOLOGIA}

A base de dados utilizada neste estudo para as estimativas econométricas é originária das respostas às pesquisas nacionais por amostra de domicílio (PNAD/IBGE). Primeiramente, serão mencionados quais os indicadores utilizados e suas respectivas estatísticas descritivas. Em seguida, serão expostas as metodologias empregadas para as estimativas das elasticidades.

A desigualdade de renda é mensurada pelo índice de Gini, amplamente utilizado na literatura econômica. O nível de renda domiciliar per capita média (valores expressos em reais de outubro de 2009) representa o crescimento econômico (ou desenvolvimento econômico, como denominado por alguns autores) de cada uma das unidades federativas. Já a pobreza é mensurada a partir do indicador de proporção de pobres em relação à população total. Os dados contemplam o período de 1995 até 2009 e abrange todos estados brasileiros, inclusive o Distrito Federal. ${ }^{9}$ Na tabela abaixo são indicadas as estatísticas descritvas, em nível, de cada uma das variáveis mencionadas:

Tabela 2 - Estatísticas descritivas (proporção de pobres, renda per capita e índice de Gini)

\begin{tabular}{c|c|c|c|c|c}
\hline Variável & Observações & Média & Desvio padrão & Mínimo & Máximo \\
\hline $\begin{array}{c}\text { Proporção de } \\
\text { pobres }\end{array}$ & 405 & 37.2856 & 16.7635 & 6.3573 & 72.5071 \\
\hline $\begin{array}{c}\text { Renda per } \\
\text { capita }\end{array}$ & 405 & 516.9394 & 212.5821 & 170.2737 & 1468.0511 \\
\hline $\begin{array}{c}\text { Coeficiente de } \\
\text { Gini }\end{array}$ & 405 & 0.5665 & 0.0435 & 0.4255 & 0.6900 \\
\hline
\end{tabular}

Fonte: cálculos próprios a partir dos dados extraídos das PNADs/IBGE.

Cabe destacar, a partir das estatísticas descritivas, que o Brasil é um país que apresenta desigualdades significativas entre seus estados, fato esse verificado para todas as variáveis de interesse. Tal condição implica que fatores históricos ou mesmo regionais podem contribuir no entendimento dessas dimensções.

Quanto ao aspecto metodológico, Datt e Ravallion (1992) partem de um modelo de regressão linear para estimar a elasticidade renda-pobreza. O modelo geral é dado pela equação:

$$
\ln \left(P_{i t}\right)=\beta_{0}+\beta_{i} \ln \left(Y_{i t}\right)+\varepsilon_{i t}
$$

onde, $P_{0}$ é a porporção de pobres, $Y$ o nível de renda per capita, os subscritos $i$ e $t$ representam a unidade federativa e o tempo, respectivamente, sendo $\varepsilon_{i t}$ o erro idiossincrático. Note bem que por se tratar de um modelo $\log$-log o coeficiente $\beta_{i}$ mede a elasticidade da pobreza em relação à renda. Portanto, tal como observam Pinto e De Oliveira (2010), é necessário que $\beta_{i}$ seja negativo para que um aumento no nível de renda resulte na redução da pobreza. Em outros termos, um aumento em $1 \%$ na renda reduza em mais de $1 \%$ a pobreza.

Partindo do pressuposto de que as unidades federativas possuem elementos específicos entre si que não oscilam no curto prazo e que o tempo é um dos fatores que determinam a

\footnotetext{
${ }^{9}$ Para o ano de 2000 foi utilizada a variável renda familiar per capita como proxy, pois não houve coleta de respostas à PNAD.
}

Econ. e Desenv., Santa Maria, vol. 26, n.2, p. 21 - 42, jul. - dez. 2014 
trajetória das variáveis em análise, é útil a adoção do procedimento de dados em painel para obtenção das estimativas das elasticidades.

A metodologia de dados em painel permite a estimativa através dos métodos de efeitos fixos (FE), efeitos aleatórios (RE) ou primeiras diferenças (FD). O procedimento de estimação por efeitos fixos consiste no controle das variáveis omitidas, em outras palavras, na remoção de variáveis explicativas constantes ao longo do tempo, mas que variam entre as unidades federativas. ${ }^{10}$ Assim, a forma função passa a ser:

$$
\ln \left(P_{i t}\right)=\beta_{1} \ln \left(Y_{i t}\right)+a_{i}+\varepsilon_{i t}
$$

onde, $a_{i}=\alpha+\beta_{2} \gamma_{i}$ e $\gamma_{i}$ representa a variável omitida. Neste caso, o termo $a_{i}$ está supostamente correlacionado com as variáveis explicativas em todos instantes de tempo e sua exclusão resultará em estimadores ineficientes. Contudo, se for considerada a possibilidade de que $a_{i}$ é independente da matriz de variáveis explicativas em todos instantes de tempo, então o modelo de efeitos aleatórios é dado por:

$$
\ln \left(P_{i t}\right)=\beta_{0}+\beta_{1} \ln \left(Y_{i t}\right)+\beta_{2} \gamma_{i}+\beta_{3} \omega_{t}+\varepsilon_{i t}
$$

onde, $\beta_{0}$ representa o efeito não observado de média zero e $\omega_{t}$ representa a variável omitida não correlacionada com as variáveis explicativas. Note que $\omega_{t}$ contém apenas o subscrito $t, \mathrm{o}$ qual indica que varia ao longo do tempo, mas é constante entre os estados.

É ainda adicionado às estimativas os níveis iniciais das variáveis de interesse, tal como sugere Bourguignon (2002), configurando o modelo de primeiras-diferenças:

$$
\Delta \ln \left(P_{i t}\right)=B_{1} \Delta \ln \left(Y_{i t}\right)+\Delta \varepsilon_{i t}
$$

A opção pela estimativa contemplando os níveis iniciais de renda, pobreza e desigualdade é justificada pelos estados apresentarem distintas condições iniciais dessas dimensões. Bourguignon (2002) oferece uma análise a respeito desta questão demonstrando que os níveis iniciais de desenvolvimento e também de desigualdade influenciam a trajetória da pobreza. Além disto, sugere que o trade-off entre crescimento econômico e desigualdade pode ser explicado pelos respectivos níveis iniciais de desigualdade e desenvolvimento.

Sob (1), ainda são considerados elementos da discussão teórica, essencialmente o efeito da desigualdade sobre a pobreza, tal como sugerem Ravallion e Chen (1997) e Datt e Ravallion (1992). Neste caso, é incorporada esta variável (mensurada pelo índice de Gini $G$ ). Serão ainda incluídas variáveis dummies para efeitos temporais, desse modo passando a função a ter a seguinte forma funcional:

$$
\ln \left(P_{i t}\right)=\beta_{0}+B_{1} \ln \left(Y_{i t}\right)+\beta_{2} \ln \left(G_{i t}\right)+\beta_{3 t} D+\varepsilon_{i t}
$$

Dessa forma, é obtida a elasticidade redistribuição-pobreza. Segundo Adams (2002), o efeito que o crescimento econômico exerce sobre a pobreza é dado pelo grau de desigualdade, então a desigualdade deve ser utilizada como controle para qualquer função de pobreza.

\footnotetext{
${ }^{10}$ Caso $a_{i}$ a seja correlacionado com quaisquer variáveis explicativas, as estimativas serão viesadas e inconsistentes, portanto, é necessário que as variáveis explicativas sejam estritamente exógenas após retirar o efeito não observado $a_{i}$ (WOOLDRIDGE, 2006, pg. 424).
} 
Haque (2009) propõe, a partir de quatro distintas formas funcionais, a estimativa da elasticidade renda-desigualdade, obtida pelo método de mínimos quadrados ordinários (MQO). A especificação semi-log duplo proposta pelo autor é dada por: ${ }^{11}$

$$
G=\beta_{0}+\beta_{1}(Y)+\gamma \ln (Y)+\varepsilon
$$

onde, $G$ representa a medida de desigualdade de renda e $\beta_{1}$ e $\gamma$ são coeficientes da regressão. Neste caso, o cálculo da elasticidade é dado por $\left(\beta_{1}+\gamma\right) / Y$. De maneira alternativa, o presente estudo propõe o seguinte modelo, a partir da forma funcional log-log:

$$
\ln G_{i t}=\beta_{0}+\beta_{1} \ln \left(Y_{i t}\right)+\varepsilon_{i t}
$$

Dentro deste contexto e assumindo que a pobreza pode exercer efeito sobre a distribuição de renda, adapta-se o modelo de Haque (2009) para que seja incorporada uma medida de pobreza para obtenção da elasticidade pobreza-desigualdade, tal como segue:

$$
\ln G_{i t}=\beta_{0}+\beta_{1} \ln \left(Y_{i t}\right)+\beta_{2} \ln \left(P_{i t}\right)+\varepsilon_{i t}
$$

Adicionalmente, serão reportados os resultados dos testes de especificação de Breusch-Pagan, de Wooldridge e Jarque-Bera. O primeiro deles indica qual o modelo mais adequado (efeitos fixos ou aleatórios) sob a hipótese de que as variáveis explicativas possam ser correlacionadas com o termo de erro. Neste caso, são dadas as seguintes hipóteses: $H_{0}: \operatorname{Cov}\left(b^{v i}-b\right)=0$ e $H_{1}: \operatorname{Cov}\left(b^{v i}-b\right) \neq 0$, ou então, $\operatorname{Cov}\left(b^{v i}\right)=\hat{\beta}_{E F}$ e $\operatorname{Cov}(b)=\hat{\beta}_{E A}$. Em outros termos, a hipótese nula é de que o erro idiossincrático não possui correlação com as variáveis explicativas no modelo de efeitos aleatórios através das diferenças entre as variâncias dos estimadores de efeitos fixos e aleatórios. Se a hipótese nula for rejeitada, então o modelo de efeitos fixos é mais consistente que o modelo de efeitos aleatórios (VASCONCELLOS e ALVES, 2000).

O teste de Wooldridge, por sua vez, se refere à correlação serial. Segundo Wooldridge (2002, pgs. 282-283), no modelo de primeiras diferenças, os erros $\varepsilon_{i t} \equiv \Delta u_{i t}$ deveriam ser serialmente não correlacionados. Para tanto, fornece um teste de exogeneidade estrita com $T-2$ períodos de tempo. A forma funcional é do tipo:

$$
\hat{\varepsilon}_{i t}=\hat{\rho}_{1} \hat{\varepsilon}_{i, t-1}+\mu_{i t}, t=3,4, \ldots, T \text { e } i=1,2, \ldots, N
$$

Se os erros idiossincráticos $\left\{u_{i t}: t=1,2, \ldots, T\right\}$ são correlacionados, então $\left\{\varepsilon_{i t}: t=1,2, \ldots, T\right\}$ serão autocorrelacionados. Sendo a hipótese nula que não há correlação serial nos resíduos para primeiras diferenças, então $\operatorname{Corr}\left(\varepsilon_{i t}, \varepsilon_{i, t-1}\right)=-0.5$. Havendo correlação serial significante em $\varepsilon_{i t}$, então é possível o cálculo do estimador da matriz de variância robusta para o estimador de primeiras diferenças.

Por sua vez, o teste de Breusch-Pagan do tipo Langrange Multiplier testa a existência de heterogeneidade não observada. Dadas as seguintes hipóteses: $H_{0}: \operatorname{Var}\left(\mu_{i}\right)=0$ e $H_{1}: \operatorname{Var}\left(\mu_{i}\right) \neq 0$. O teste é do tipo:

\footnotetext{
11 Além da forma funcional semi-log duplo (DSL), Haque (2009) utiliza as formas funcionais linear (L), quadrática (QAD) e semi-log (SL) em suas estimativas.
} 


$$
L M=\frac{n T}{2(T-1)}\left[\frac{\sum_{i}\left(\sum_{t} e_{i t}\right)}{\sum_{i} \sum_{t} e_{i t}^{2}}-1\right]^{2}, \text { sendo } i=1, \ldots, N \text { e } t=1, \ldots, T
$$

O teste possui distribuição qui-quadrada com um grau de liberdade, ou seja, $\chi_{1}^{2}$. Se rejeitada a hipótese nula, então há heterogeneidade não observada no modelo, em outros termos, admite-se o modelo de efeitos aleatórios.

O teste de normalidade de Jarque-Bera é dado pelo cálculo da assimetria e curtose dos resíduos de mínimos quadrados ordinários (GUJARATI, 2000). A hipótese nula é de que os resíduos possuem distribuição qui-quadrado com dois graus de liberdade, ou seja, $\chi_{2}^{2}$. $\mathrm{O}$ cálculo é dado por:

$$
J B=n\left[\frac{A^{2}}{6}+\frac{(C-3)^{2}}{24}\right]
$$

onde, $A$ é a assimetria e $C$ é a curtose. Se o valor da estatística for elevado, então se rejeita a hipótese de normalidade.

Assim como para as estimativas da elasticidade renda-pobreza também será empregada a metodologia de dados em painel para obtenção das demais elasticidades. Somam-se ainda os procedimentos referentes aos testes de especificação e a estimação com as variáveis dummies para efeitos temporais, mencionados nesta seção.

A seguir serão reportados os resultados para as elasticidades renda-pobreza, redistribuição-pobreza, renda-desigualdade e pobreza-desigualdade, bem como a contribuição deste método na formulação de políticas públicas.

\section{RESULTADOS}

A princípio, vale mencionar que todos os coeficientes estimados são robustos com correção de White e expressos sob a forma funcional log-log. Deve-se ainda considerar que as notações $* * *, * *$ e * representam significância estatística ao nível de 1\%, 5\% e 10\%, respectivamente. Serão apresentados os resultados para os modelos de efeitos fixo, aleatóro e primeiras diferenças referentes a elasticidades renda-pobreza, tal como sugerido por Datt e Ravallion (1992); elasticidade redistribuição-pobreza, conforme Ravallion e Chen (1997); e, elasticidade renda-desigualdade, proposta por Haque (2009), além da elasticidade pobrezadesigualdade, adaptada do modelo de Haque.

De uma forma geral, os resultados obtidos para a elasticidade renda-pobreza demonstram que há uma correlação negativa entre o nível de pobreza e a renda per capita média. Partindo, por exemplo, do modelo 1 , um aumento de $1 \%$ na renda gera uma redução de $0,9 \%$ na proporção de pobres. Neste caso, deriva-se que políticas que promovam unicamente o aumento da renda média contribuem diretamente na redução da pobreza.

RE\&D Econ.e Desenv., Santa Maria, vol. 26, n.2, p. 21 - 42, jul. - dez. 2014 
Tabela 3 - Elasticidade renda-pobreza - Proporção de pobres (variável dependente)

\begin{tabular}{l|c|c|c}
\hline Variáveis independentes & Modelo 1 - FE & Modelo 2 - RE & Modelo 3 - FD \\
\hline Intercepto & $9.0779^{* * *}$ & $9.7765^{* * *}$ & $-5.8272^{* * *}$ \\
\hline Renda per capita & $-0.9332^{* * *}$ & $-1.0083^{* * *}$ & $-0.0495^{* * *}$ \\
\hline Dummies temporais? & Sim & Sim & Sim \\
\hline $\mathrm{R}^{2}$ & 0.8131 & 0.8169 & 0.6953 \\
\hline Estatística F (Prob>F) & $55.53(0.00)$ & & $228.64(0.00)$ \\
\hline Teste de Wald (Porb>chi
\end{tabular}

Fonte: Elaboração própria dos autores

Com a incorporação do indicador de desigualdade (índice de Gini) é possível obter a elasticidade redistribuição-pobreza. A partir do modelo de efeitos aleatórios o resultado sugere que o aumento de $1 \%$ na renda média da população resulta, em média, em uma queda de $0,9 \%$ na proporção de pobres. Por outro lado, uma redução de $1 \%$ na desigualdade de renda representa, em média, uma queda de $1,8 \%$ na pobreza.

Tabela 4 - Elasticidade redistribuição-pobreza - Proporção de pobres (variável dependente)

\begin{tabular}{l|c|c|c}
\hline Variáveis independentes & Modelo 1 - FE & Modelo 2 - RE & Modelo 3 - FD \\
\hline Intercepto & $9.5111^{* * *}$ & $10.2213^{* * *}$ & $-11.9514 * * *$ \\
\hline Renda per capita & $-0.8240^{* * *}$ & $-0.9055^{* * *}$ & $-0.0491^{* * *}$ \\
\hline Índice de Gini & $1.8040^{* * *}$ & $1.8409^{* * *}$ & $98.3155^{* * *}$ \\
\hline Dummies temporais? & $\mathrm{Sim}$ & $\mathrm{Sim}$ & Sim \\
\hline $\mathrm{R}^{2}$ & 0.8859 & 0.8897 & 0.8103 \\
\hline Estatística F (Prob>F) & $75.61(0.00)$ & $59649.45(0.00)$ & $582.85(0.00)$ \\
\hline $\begin{array}{l}\text { Teste de Wald } \\
(\text { Porb>chi }\end{array}$ & & & \\
\hline
\end{tabular}

Fonte: Elaboração própria dos autores

A adição do componente de desigualdade revela que, a princípio, políticas que busquem uma melhora na distribuição da renda são mais efetivas no combate à pobreza do que as que objetivam unicamente o aumento no nível de renda. Na realidade, tal como observam Pinto e Oliveira (2010), esta conclusão pode ser precipitada, pois os indicadores de renda e desigualdade não oscilam na mesma escala (o primeiro assume quaisquer valores positivos, ao passo que o segundo limita-se ao intervalo 0 à 1). Ademais, ainda é possível notar que a elasticidade redistribuição-pobreza indica maior poder explicativo em comparação à elasticidade renda-pobreza.

Para o teste de Breusch-Pagan houve a rejeição da hipótese nula em ambas as situações. Essa condição indica a presença de heterogeneidade não observada. A hipótese nula para o teste de Wooldridge para dados em painel revela ausência de autocorrelação dos erros. Assim, o modelo de efeitos fixos apresenta estimadores mais eficientes em comparação ao modelo de primeiras diferenças. Por fim, para o teste de normalidade de Jarque-Bera aponta para a rejeição da hipótese nula de que os resíduos se distribuem normalmente para as variáveis taxa de pobreza e índice de Gini, mas não é rejeitada a hipótese nula para a variável renda per capita média.

A título de comparação, os resultados obtidos para as elasticidades renda-pobreza e redistribuição-pobreza neste estudo se aproximam de outros trabalhos realizados para o Brasil ao indicar que a desigualdade contribui de maneira mais representativa do que o aumento da renda para os mais pobres (MARINHO e SOARES, (2003); DE FRANÇA, (2010), PINTO E OLIVEIRA (2010), COELHO (2009), NEDER (2004); HOFFMANN (2005)). Contudo, há 
de se ressaltar que a magnitude das elasticidades varia entre os trabalhos pela metodologia econométrica, pelas formas funcionais adotadas nos modelos, pelos indicadores utilizados ou mesmo o nível de análise.

Agora, a análise contempla as elasticidades renda-desigualdade e pobrezadesigualdade. Os resultados obtidos para a elasticidade renda-desigualdade não indicam significância estatística para os modelos FE e FD, inclusive ao nível de $10 \%$.

Tabela 5 - Elasticidade renda-desigualdade - Índice de Gini (variável dependente)

\begin{tabular}{l|c|c|c}
\hline Variáveis independentes & Modelo 1 - FE & Modelo 2 - RE & Modelo 3 - FD \\
\hline Intercepto & -0.2401 & -0.1004 & $-0.0633^{* * *}$ \\
\hline Renda per capita & -0.0605 & $-0.0598^{* *}$ & $-4.15 \mathrm{e}-06$ \\
\hline Dummies temporais? & Sim & Sim & Sim \\
\hline $\mathrm{R}^{2}$ & 0.3939 & 0.3940 & 0.5011 \\
\hline Estatística F & $38.44(0.00)$ & & $248.40(0.00)$ \\
\hline Teste de Wald & & $4531.70(0.00)$ & \\
\hline
\end{tabular}

Fonte: Elaboração própria dos autores

Apenas para o modelo RE a variável renda per capita média é significante, porém, ao nível de 5\%. Para este modelo o aumento de $1 \%$ no crescimento econômico, representado pela variável renda per capita média, indica uma queda de $0,05 \%$ na desigualdade de renda, mensurada pelo índice de Gini. Então, de maneira comparativa, o efeito do aumento da renda sobre a desigualdade é menor que o efeito sobre a pobreza (para o mesmo modelo de efeitos aleatórios).

Por fim, a elasticidade pobreza-desigualdade aponta que a inclusão da variável proporção de pobres auxilia no entendimento da determinação da desigualdade. Para os três modelos estimados os resultados são estatisticamente significantes ao nível de $1 \%$.

Partindo do modelo de efeitos fixos pode ser visto que o aumento de $1 \%$ na renda aumenta em $0,1 \%$ a desigualdade de renda, distintamente do que se esperava. Por outro lado, a redução de $1 \%$ na pobreza implica na queda de $0,1 \%$ na desigualdade. Logo, políticas que promovam a redução da pobreza são mais indicadas para reduzir a desigualdade de renda na população. Note bem que, tal como mencionado anteriormente, as variáveis analisadas possuem magnitudes distintas.

Tabela 6 - Elasticidade pobreza-desigualdade - Índice de Gini (variável dependente)

\begin{tabular}{l|c|c|c}
\hline Variáveis independentes & Modelo 1 - FE & Modelo 2 - RE & Modelo 3 - FD \\
\hline Intercepto & $-1.9717^{* * *}$ & $-2.0743^{* * *}$ & $0.0846^{* * *}$ \\
\hline Renda per capita & $0.1175^{* * *}$ & $0.1341^{* * *}$ & $0.0001^{* * *}$ \\
\hline Proporção de Pobres & $0.1907 * * *$ & $0.1858^{* * *}$ & $0.0038^{* * *}$ \\
\hline Dummies temporais? & Sim & Sim & Sim \\
\hline $\mathrm{R}^{2}$ & 0.6087 & 0.6298 & 0.6894 \\
\hline Estatística F & $43.55(0.00)$ & & $353.74(0.00)$ \\
\hline Teste de Wald & & $8588.08(0.00)$ & \\
\hline
\end{tabular}

Fonte: Elaboração própria dos autores

Quanto aos testes econométricos, a estatística de Breusch-Pagan leva à rejeição da hipótese nula para ambas as elasticidades, cuja variável dependente é a medida de desigualdade. Para o teste de Wooldridge, por sua vez, rejeita-se a hipótese nula ao nível de $5 \%$.

RE\&D Econ.e Desenv., Santa Maria, vol. 26, n.2, p. 21 - 42, jul. - dez. 2014 
Deve ser ressaltado o fato de que a análise proposta neste artigo envolve as elasticidades para o Brasil como um todo a partir da metodologia de dados em painel. Note ainda que as estimativas indicam que variáveis utilizadas, a saber, o índice de Gini, a proporção de pobres e a renda per capita média relacionam-se entre si, o que pode ser observado através do $\mathrm{R}^{2}$ para todos os modelos quando da incorporação dos indicadores.

Quanto às políticas públicas, é possível relatar que as destinadas à melhoria na distribuição de renda tendem a ser mais efetivas no combate à pobreza do que as que promovam unicamente o aumento da renda média, tal como sugerem outras evidências empíricas para o Brasil em distintos níveis de agregação. Em contrapartida, políticas que visam a contenção da pobreza tendem a ser mais efetivas na melhoria da distribuição de renda.

De fato, isto pode ser corroborado através da agenda social implantada no país a partir de meados da década de 1990. O Brasil a partir desse período promoveu uma série de políticas sociais com o intuito de reduzir a pobreza e prover a melhoria na distribuição de renda. Como reflexo, os dispêndios associados aos programas de transferência de renda, o aumento do salário mínimo, aliado ao aumento da renda per capita média, contribuíram em grande medida para a redução da desigualdade de renda e da pobreza.

\section{CONCLUSÃO}

O objetivo principal deste trabalho foi de identificar relações entre nível de renda, pobreza e desigualdade através da estimativa das elasticidades renda-pobreza, redistribuiçãopobreza, renda-desigualdade e pobreza-desigualdade. A justificativa para a investigação reside no fato de que, conforme sugere a literatura, as variáveis de interesse podem contribuir na elaboração e condução de políticas mais igualitárias.

A análise utilizou como fonte de dados o nível de renda per capita média, a proporção de pobres e o índice de Gini como indicadores de renda, pobreza e desigualdade, respectivamente, para todas as unidades federativas do Brasil, inclusive o Distrito Federal, no período entre 1995 e 2009. Para tanto, fez uso da metodologia de dados em painel (primeirasdiferenças, efeitos fixos e aleatórios).

Os resultados obtidos a partir das elasticidades indicam que as políticas destinadas à melhoria na distribuição de renda são mais efetivas no combate à pobreza do que as que promovam unicamente o aumento da renda média. Em contrapartida, políticas que visam a contenção da pobreza tendem a ser mais efetivas na melhoria da distribuição de renda.

Observa-se ainda que para trabalhos futuros a incorporação de variáveis dummy para a estimativa das elasticidades por estado permitirá observar o desempenho específico de cada unidade federativa. Dessa forma, é possível identificar as diferenças de magnitude entre as elasticidades das unidades federativas e também qual tipo de política social contribuíria de maneira mais representativa no combate à pobreza e a desigualdade. 


\section{REFERÊNCIAS BIBLIOGRÁFICAS}

AARON, H. The Foundations of the War on Poverty Reexamined. American Economic Review, n. 57, Dezembro, pgs. 1229-1240, 1967.

ADAMS, R. J. Economic Growth, Inequality, and Poverty: Findings From a New Dataset. World Bank Policy Research Working Paper n. 2972, Washington, D.C., 2002.

ADAMS, R.H. Economic Growth, Inequality, and Poverty: Estimating the Growth Elasticity of Poverty, World Development, vol.32, n.12, pgs.1989-2014, 2004.

AGHION, P.; BOLTON, P. A trickle-down theory of growth and development with debt overhang. Review of Economic Studies, 64(2), pgs. 151-172, 1997.

AGHION, P.; CAROLI, E.; GARCIA-PENALOSA, C. Inequality and Economic Growth : The Perspective of New Growth Theory, Journal of Economic Literature, n. 37(4), pgs. 1615-1660, 1999.

ALESINA, A.; PEROTTI, R. Income distribution, political instability and investment. European Economic Review, 40(6), 1996.

ALESINA, A.; RODRIK, D. Distributive Politics and Economic Growth. Quarterly Journal of Economics, n. 109(2), 1994.

ANDERSON, W.H. L.. Trickling down: The relationship between economic growth and the extent of poverty among american families. The Quarterly Journal of Economics, Vol. LXXVIII, n. 4, pgs. 511-524, 1964.

ARAUJO, T.; FIGUEIREDO, L.; SALVATO, M. A. As inter-relações entre pobreza, desigualdade e crescimento nas mesorregiões mineiras 1970-2000. Pesquisa e Planejamento Econômico, Rio de Janeiro, v. 39, pgs. 81-119, 2009.

BANERJEE, A.; NEWMAN, A. Occupational choice and the process of development. Journal of Political Economy, University of Chicago Press, vl. 101(2), pgs. 274-298, 1993).

BARRETO, F. A. Crescimento economico, pobreza e desigualdade: o que sabemos sobre eles? Série ensaios sobre pobreza, n. 1, LEP, 2005.

BARRO, R. Inequality and Growth in a Panel of Countries. Journal of Economic Growth, n. 5, 2000.

BARROS, L. C.; GOMES, F. A. R. Desigualdade e desenvolvimento: a hipótese de Kuznets é valida para os municípios brasileiros? São Paulo: IBMEC, Working Paper, n. 28, 2007.

BOURGUIGNON, F. Pareto-Superiority of Unegalitarian Equilibria in Stiglitz' Model of Wealth Distribution with Convex Savings Function. Econometrica, n. 49, 1981.

. The growth elasticity of poverty reduction: explaining heterogeneity across countries and time periods. Paris, Fr: DELTA, Working paper 2002-03, 2002.

The Social Consequences of Economic Growth. AGHION, P., DURLAUF, S (eds), The Handbook of Economic Growth, Amsterdam, Elsevier, 2004.

BOURGUIGNON, F.; FERREIRA, F.; WALTON, M. Equity, efficiency and inequality traps: A research agenda, Journal of Economic Inequality, Springer, vl. 5(2), pgs. 235-256, 2007.

BREUSCH, T.; PAGAN, A. The LM test and its applications to model specification in econometrics. Review of Economic Studies. Vol. 47, pgs. 239-254, 1980.

CHEN, S.; RAVALLION, M. What Can New Survey Data Tell Us about Recent Changes in Distribution and Poverty?, World Bank Economic Review, 11(2), 357-82, 1997.

COELHO, J. A. Os efeitos da renda e da desigualdade na redução da extrema indigência no Brasil. 40 f. Dissertação (Mestrado em Economia) - Curso de Pós-Graduação em Economia - CAEN, Universidade Federal do Ceará, Ceará, 2009.

COMIM, F.; BAGOLIN, I. P. Aspectos qualitativos da pobreza no Rio Grande do Sul. In: Anais do I Encontro de Economia Gaúcha, Porto Alegre: PUCRS, 2002. 
DATT, G. e RAVALLION, M. Growth and Redistribution Component of changes in poverty measures: A decomposition with applications to Brazil and India in the 1980s. Journal of Development Economics, v. 38, n. 2, p. 275-295, 1992.

DE FRANÇA, J. M. S. Crescimento pró-pobre no Brasil: Impactos regionais. 2010, $104 \mathrm{f}$. Tese (Doutorado em Economia) - Escola de Pós-Graduação em Economia - EPGE, Fundação Getúlio Vargas, Rio de Janeiro, 2010.

DE JANVRY, A.; SADOULET, E.. Growth, poverty and inequality in Latin America: a causal analysis, 1970-94. Review of Income and Wealth, Series 46(3), pgs. 267-87, 2000.

DE LIMA, F. S., BARRETO, F. A.; MARINHO, E. Impacto do Crescimento Econômico e da Concentração de Renda sobre o Nível de Pobreza dos Estados Brasileiros. In: Anais do VII Encontro Regional de Economia, Fortaleza. 2003.

DEININGER, K.; SQUIRE, L. A New Data Set Measuring Income Inequality, The World Bank Economic Review, 10(3), pgs. 565-591, 1996.

DENINGER, K.; SQUIRE, L. New Ways of Looking at Old Issues: Asset Inequality and Growth. Journal of Development Economics, n. 57. 1998.

DOLLAR, D.; KRAAY, A. Growth is Good for the Poor. Journal of Economic Growth, v. 7, n. 3, p. 195-225, 2002.

EASTERLY, W. Life During Growth: International Evidence on Quality of Life and Per Capita Income. Journal of Economic Growth, 4, 1999.

FIELDS, G. S. A Class of Decomposable Poverty Measures. Distribution and Development. New York: Russell Sage Foundation, 2001.

FOSU, A. K. Inequality, income and poverty: comparative global evidence. United Nations Universirt, Working Paper n. 93, 2010.

GALOR, O.; ZEIRA, J. Income distribution and macroeconomics. Review of Economic Studies, n. 60, p. 35-52, 1993.

GUJARATI, D. N. Econometria Básica. Pearson Makron Books, 3. ed., 2000.

HAQUE, M. O. Economic Development and Its Effect on Income Distribution: Evidence from Australia. CENTRUM Catolica an International Journal, n. 3, 2009.

HIRSCH, B. T. Poverty and Economic Growth: Has Trickle Down Petered Out? Economic Inquiry, 18, pgs. 151-157, 1980.

HOFFMANN, R. Elasticidade da Pobreza em Relação à Renda Média e à Desigualdade no Brasil e nas Unidades da Federação. Revista Economia, 2005.

JUSTMAN, M.; GRADSTEIN, M. Industrial Revolution, Political Transition and the Subsequent Decline in Inequality in Nineteenth-Century Britain. Explorations in Economic History, n. 36, pgs. 109-127, 1999.

KAKWANI, N; KHANDKER, S; SON, H. Pró-pobre growth: concepts and measurement with country case studies. Brasília: International Poverty Centre/PNUD, working paper 01. 2004.

KAKWANI, N.; PERNIA, E. M. What is pro-poor growth? Asian Development Review, v.18, $\mathrm{n}^{\circ} 1,2000$.

KAKWANI, N.; Son, H. H. Pro-poor Growth and Poverty Reduction: The Asian Experience, the Poverty Center, Office of Executive Secretary, ESCAP, Bangkok, 2002.

KIMENYI, M. S. Economic reforms and pro-poor growth: Lessons for Africa and other developing regions and economies in trasition. University of Connecticut, Working Papers n. 02, 2006.

KUZNETS, S. Economic Growth and Income Inequality, American Economic Review, pgs. $1-28,1955$.

MARINHO, E.; SOARES, F. Impacto do crescimento econômico e da concentração de renda sobre a redução da pobreza nos estados brasileiros. In: Anais do XXXI Encontro Nacional de Economia, Porto Seguro, 2003. 
MATIAS, J. S.; SALVATO, M. A.; BARRETO, F. A. Análise da qualidade do crescimento econômico nos estados brasileiros de 1995 à 2008: Quão elásticos são os indicadores de pobreza com relação ao crescimento? In: XXXVIII Encontro Nacional de Economia, Salvador, 2010.

MENG, X.; GREGORY, R.; WANG, Y. Poverty, inequality, and growth in urban China, 1986-2000. Journal of Comparative Economics, v. 33, n. 4, p. 710-729, 2005.

MIRRLESS, J. An exploration in the theory of optimum income taxation. Review of Economic Studies, n. 38, 175-208, 1971.

NEDER, H. D. Desenvolvimento de metodologias estatísticas aplicadas aos dados das PNADs. In CAMPANHOLA, C.; GRAZIANO, J. S. (eds), O Novo Rural Brasileiro: Rendas das Famílias Rurais. Embrapa, Brasília. Vol.5, 2004.

PERL, L.; SOLNICK L. A Note on Trickling Down. Quarterly Journal of Economics, n. 85, pgs. 171-178, 1971.

PERSSON, T.; TABELLINI, G. Is Inequality Harmful for Growth?” American Economic Review, N. 84(3), pgs. 600-621, 1994.

PIKETTY, T.; SAEZ, E. Income inequality in the United States, 1913-1998. The Quartely Journal of Economics, vol. CXVIII, 2003.

PINTO, M. S.; DE OLIVEIRA, J. C. Crescimento pró-pobre: Análise dos estados brasileiros entre 1995 e 2007. Revista de Economia Contemporânea, Rio de Janeiro, v. 14, n. 2, pg. 327-358, maio/ago, 2010.

PLOTNICK, R; SKIDMORE, F. Progress Against Poverty. New York: Academic Press, 1975.

PSACHAROPOULOS, G.; MORLEY, S.; FISZBEIN, A.; LEE, H.; WOOD, W. Poverty and Income Inequality in Latin America During the 1980s, Review of Income and Wealth, Série 41, n. 3, pgs. 245-64, Setembro, 1995.

RAVALLION, M. Growth and Poverty: Evidence for Developing Countries in the 1980s', Economics Letters, 48, 411-417, 1995.

. Can High-Inequality Developing Countries Escape Absolute Poverty?

Economic Letters, v. 56, p. 51-57, 1997.

Paper n ${ }^{\circ} 3242,2004$.

. Pro-poor growth: a primer. World Bank Policy Research, Working

RAVALLION, M.; CHEN, S. What Can New Survey Data Tell Us About Recent Changes in Distribution and Poverty? The World Bank Economic Review, 11(2), pgs. 357-382, 1997.

. Measuring pro-poor growth. World Bank Policy Research,

Working Paper $\mathrm{n}^{\circ}$ 2666, 2003, Washington.

RAY, D. Development Economics. Editora IE-Princeton, 1998.

RESENDE, G. M. O crescimento econômico dos municípios mineiros tem sido pró-pobre? Uma análise para o período 1991-2000. Nova Economia, Universidade Federal de Minas Gerais, vl. 18, pgs. 119-154, 2008.

RODRIK, D. What does the political economy literature on trade policy (not) tell us that we ought to know?. NBER Working Paper, n. 4870, 1994.

SALVATO, M. A.; ARAUJO JUNIOR, A. F.; MESQUITA, L. A. Crescimento pró-pobre no Brasil: Uma avaliação empírica da década de 1990. IBMEC-MG, Belo Horizonte, Working Paper n. 43, 2007.

SEN, A. Desigualdade reexaminada. Rio de Janeiro: Record, 2001.

SILVEIRA NETO, R. Quão pró-pobre tem sido o crescimento econômico no nordeste? Evidência para o período 1991-2000. In: Anais do X Encontro Regional de Economia, 2005, Fortaleza.

SON, H. H. A note on pro-poor growth. School of Economics of Macquarie University, 2003.

RE\&D Econ.e Desenv., Santa Maria, vol. 26, n.2, p. 21 -42, jul. - dez. 2014 
A note on pro-poor growth. Economics Letters, n. 82 p. 307-314, 2004.

. Interrelationship between growth, inequality, and poverty: The asian experience.

Asian Development Review, vol. 25, n.2, pgs. 37-63, 2007.

STEVANS, L. K.; SESSIONS, D. N. The relationship between poverty, economic growth, and inequality revisited. Research Zarb School of Business, 2002.

TOCHETTO, D. G.; RIBEIRO, E. P; COMIM, F. V.; PORTO JUNIOR, S. S. Crescimento pró-pobre no Brasil - uma análise exploratória. In: Anais do XXXII Encontro Nacional de Economia, 2004, João Pessoa.

THORNTON, J.R.; AGNELLO, R. J.; LINK, C. R. Poverty and Economic Growth: Trickle Down Peters Out. Economic Inquiry, n. 26, pgs. 385-394, 1978.

TODARO, M. P.; SMITH, S. C. Economic development. 8. Ed. Reino Unido: Addison Wesley, 2003.

VASCONCELlOS, M. A. S.; ALVES, D. Manual de econometria. Editora Atlas, 2000.

WOOLDRIDGE, J. M. Econometric Analysis of Cross Section and Panel Data. MIT PRESS, 2001.

WOOLDRIDGE, J. M. Introdução à econometria: Uma abordagem moderna. São Paulo: Thomson, 2006.

WODON, Q. T. Growth, Poverty, and Inequality: A Regional Panel for Bangladesh. World Bank Policy Research Working Paper, n. 2072, 1999. 


\section{APÊNDICE A - Testes econométricos}

A.1 - Elasticidade renda-pobreza

Jarque-Bera

Logaritmo taxa de pobreza

Normality test: $23.88 \mathrm{Chi}(2) \quad 6.5 \mathrm{e}-06$ - Test for Ho: normality

Logaritmo renda per capita

Normality test: 5.097 Chi(2) .0782 - Test for Ho: normality

Logaritmo gini

Normality test: $12.1 \mathrm{Chi}(2) .0024$ - Test for Ho: normality:

Breusch-Pagan

Breusch and Pagan Lagrangian multiplier test for random effects:

Test: $\operatorname{Var}(\mathrm{u})=0-\operatorname{chi} 2(1)=1390.72-$ Prob $>\operatorname{chi} 2=0.0000$

Teste de Wooldridge

H0: no first-order autocorrelation $-\mathrm{F}(1,26)=34.975-$ Prob $>\mathrm{F}=0.0000$

A.2 - Elasticidade redistribuição-pobreza

Breusch-Pagan

Test: $\operatorname{Var}(\mathrm{u})=0-\operatorname{chi} 2(1)=1198.21-$ Prob $>$ chi $2=0.0000$

Teste de Wooldridge

H0: no first-order autocorrelation $-\mathrm{F}(1,26)=31.491-$ Prob $>\mathrm{F}=0.0000$

A.3 - Elasticidade renda-desigualdade

Breusch-Pagan

Test: $\operatorname{Var}(\mathrm{u})=0-\operatorname{chi} 2(1)=1027.93-$ Prob $>\operatorname{chi} 2=0.0000$

Teste de Wooldridge

H0: no first-order autocorrelation $-\mathrm{F}(1,26)=4.360-$ Prob $>\mathrm{F}=0.0467$

A.4 - Elasticidade pobreza-desigualdade

Breusch-Pagan

Test: $\operatorname{Var}(\mathrm{u})=0-\operatorname{chi} 2(1)=863.43-$ Prob $>$ chi $2=0.0000$

Teste de Wooldridge

H0: no first-order autocorrelation $-\mathrm{F}(1,26)=4.948-$ Prob $>\mathrm{F}=0.0350$

RE\&D Econ.e Desenv., Santa Maria, vol. 26, n.2, p. 21 - 42, jul. - dez. 2014 